\title{
MEMBANGUN REPUTASI SEKOLAH MELALUI PEMBELAJARAN SENI BUDAYA DI SMP NEGERI 4 KALIJATI SUBANG
}

\author{
Sri Rochani Mulyani ${ }^{1}$, Vip Paramarta ${ }^{2}$, Nina Herlina ${ }^{3}$ \\ 1,2,3 Program Magister Manajemen Universitas Sangga Buana \\ ${ }^{1}$ korespondensi : sri.rochani@usbypkp.ac.id
}

\begin{abstract}
This research was conducted with the aim of knowing how the management of cultural arts learning carried out at SMPN 4 Kalijati Subang, whether it can improve the school's reputation. The research method uses a qualitative approach, using in-depth interview instruments from several informants, namely the Principal, Teachers, Administrative Staff, Students, Parents. Also supported by the opinions of experts, including the Head of the Education and Culture Office of Subang Regency, the School Superintendent of the Subang Regency Education and Culture Office and the Bale Kiwari Dance Studio. Informant data analysis technique using NVIVO pro12 software. The results of this study indicate that the management of art and culture learning can improve the good name of the school, by improving the infrastructure and quality of arts and culture teachers and collaboration with art studios, so as to optimize achievements in the arts and culture field.
\end{abstract}

Keywords: Management of Cultural Arts Learning and School Reputation

\begin{abstract}
ABSTRAK
Penelitian ini dilakukan dengan tujuan untuk mengetahui bagaimana pengelolaan pembelajaran seni budaya yang dilakukan di SMPN 4 Kalijati Subang, apakah dapat meningkatkan reputasi sekolah. Metode penelitian menggunakan pendekatan kualitatif, dengan menggunakan instrumen wawancara mendalam dari beberapa informan yaitu Kepala Sekolah, Guru, Staf Tata Usaha, Siswa, Orang Tua. Didukung pula dengan pendapat para ahli antara lain Kepala Dinas Pendidikan dan Kebudayaan Kabupaten Subang, Pengawas Sekolah Dinas Pendidikan dan Kebudayaan Kabupaten Subang dan Sanggar Tari Bale Kiwari. Teknik analisis data informan menggunakan software NVIVO prol2. Adapun hasil dari penelitian ini menunjukkan bahwa pengelolaan pembelajaran seni budaya dapat meningkatkan nama baik sekolah, dengan meningkatkan infrastruktur dan kualitas guru seni budaya dan kerjasama dengan sanggar seni, sehingga dapat mengoptimalkan prestasi di bidang seni budaya.
\end{abstract}

Kata kunci: Manajemen Pembelajaran Seni Budaya dan Reputasi Sekolah

\section{PENDAHULUAN}

Seni Budaya dan Keterampilan (SBK) sebagai salah satu bidang studi dalam pembelajaran dengan melihat latar belakang akan dapat menumbuhkan kecerdasan moral secara kompetitif, latar belakang tersebut sebagai berikut, yaitu bahwa muatan seni budaya dan keterampilan sebagaimana yang diamanatkan dalam peraturan Pemerintah Republik Indonesia Nomor 19 tahun 2005 tentang Standar Nasional Pendidikan tidak hanya dalam satu mata pelajaran karena budaya itu sendiri meliputi segala aspek kehidupan. Tujuan pembelajaran seni budaya yaitu untuk menumbuhkembangkan kepekaan rasa estetik dan artistik, sikap kritis, apresiatif, dan kreatif pada diri setiap peserta didik secara menyeluruh [1].

Seni Budaya Indonesia yang Termasuk Situs Warisan Dunia Unesco dari berbagai seni budaya Indonesia, beberapa di antaranya sudah terkenal di dunia : Tari Kecak, Reog 
Ponorogo, Wayang Kulit, Angklung, Batik, Candi Borobudur, Candi Prambanan, Keris, Tari Saman, Noken (tas tradisional dari Papua), Tari tradisional Bali yang meliputi Drama Tari Gambuh, Drama Tari Wayang
Wong, Tari Baris (Tari Baris Upacara), Tari Barong Ket, Tari Joget Bumbung, Tari Legong Keraton, Tari Rejang, Tari Sanghyang Dedari dan Tari Topeng Sidhakarya.

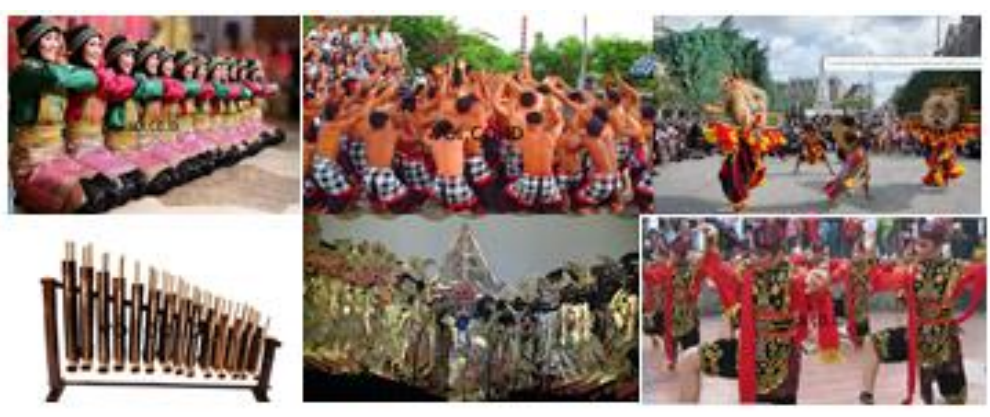

Gambar 1: Seni Budaya Indonesia

Melalui kegiatan seni budaya, dapat meningkatkan martabat daerah maupun negara. Banyak sekali kesenian daerah yang di promosikan ke manca negara, sehingga Indonesia sangat dikenal, karena keragaman seni budaya yang indah. Banyak para turis yang tertarik untuk mengetahui dan belajar berbagai seni budaya, diantaranya seni tari, angklung sdb. Begitupun kegiatan seni budaya dilingkungan sekolah, jika di mange dengan baik, dapat meningkatkan reputasi sekolah. Kegiatan seni budaya yang dikebangkan dilingkungan sekolah, sebanyaknya bersifat multi kultural, sehingga siswa tidak hanya mengenal seni budaya local daerah, akan tetapi mengenal seni budaya nusantara Indonesia. Penelitian ini dilakukan di SMP Negeri 4 Kalijati Subang.
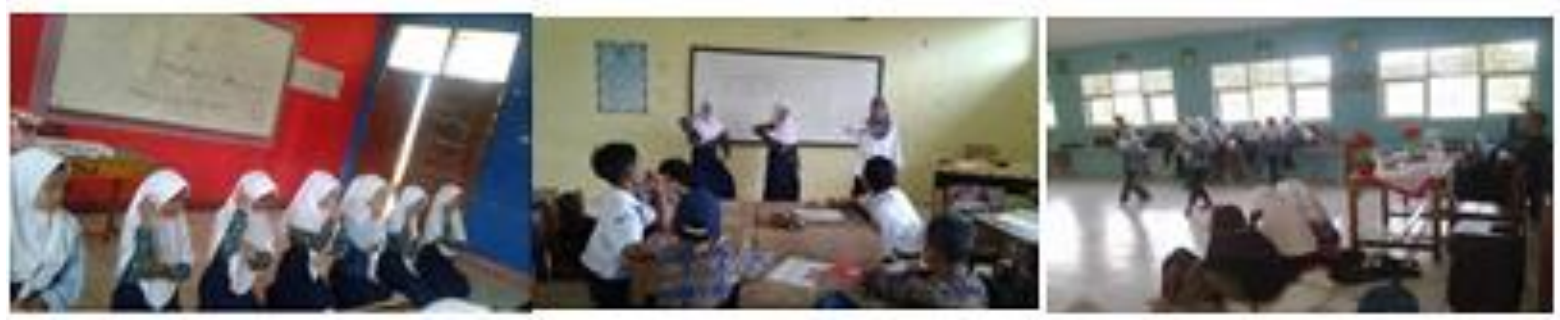

Gambar 2: Seni Budaya seni budaya di SMP Negeri 4 Kalijati Subang

SMPN 4 Kalijati Subang memiliki potensi dalam kegiatan seni budaya, yang diharapkan dapat meningkatkan reputasi sekolah. Namun demikian dalam kegiatan pembelajaran seni budaya, belum didukung sarana prasarna untuk kegiatan latihan. Sehingga potensi untuk mengikuti lomba / kejuaraan untuk optimal untuk mengangkat reputasi sekolah.

\section{TINJAUAN PUSTAKA}

Manajemen sekolah merupakan komponen yang sangatstrategis dalam proses pendidikan.

"Stakeholder yaitu Kepala sekolah dan guru memiliki kebebasan yang luas dalam mengelola sekolah tanpa mengabaikan kebijakan dan otoritas pemerintah melalui strategi seperti berikut: Kurikulum yang 
bersifat inklusif, Proses belajar-mengajar yang efektif, Lingkungan sekolah yang mendukung, Sumber daya yang berasas pemerataan, dan Standardisasi dalam hal-hal tertentu, monitoring, evaluasi, dan tes" [2].

Pembelajaran seni budaya merupakan aktivitas belajar yang menampilkan karya seni estetis, artistik, dan kreatif yang berakar pada norma, nilai, perilaku, dan produk seni budaya bangsa melalui aktivitas berkesenian [3].

Ruang lingkup pembelajaran seni budaya terdiri dari: seni rupa, seni musik, seni tari dan seni drama, (1) Seni rupa adalah ungkapan, gagasan, perasaan,emosional, dan pengalaman yang diwujudkan dalam bentuk karya dua dan tiga dimensi, (2) Seni musik adalah penangkapan suara dalam paduan keseimbangan tiga aspek yakni irama, melodi dan harmoni., (3) Seni tari adalah paduan keseimbangan unsur gerak, irama, dan rasa wiraga, wirama dan wirasa untuk ungkapan perasaan, gagasan, dan pesan dengan penunjang iringan dan latar belakang, (4) Seni drama hakikatnya sebuah seni pertunjukan atau sebuah penyajian ungkapan yang menggunakan suara, tubuh, gerak tubuh, dan latar ruang untuk menyampaikan gagasan, pesan dan perasaan dalam suatu kegiatan pagelaran [4].

Fungsi pendidikan seni dapat meningkatkan daya kreativitas anak [5]. Lowenfeld mengemukakan: pendidikan seni dapat membantu pertumbuhan mental dan kreativitas anak didik, dan menurut $\mathrm{Ki}$ Hadjar Dewantara; seni dapat menghaluskan perasaan. Margaret Numberg; seni dapat digunakan sebagai sarana terapi/kesehatan mental. Chapman; seni dapat meningkatakan kemampuan apresiasi. seiring dengan itu Kaufman juga menyatakan hal yang senada bahwa pendidikan seni dapat memgembangkan imajinasi, kreativitas dan kemampuan artistik serta intelektual. berbagai pemikiran ini pendidikan seni memiliki fungsi utama sebagai alat atau media pendidikan disamping sebagai sarana mengembangkan kemampuan di bidang seni itu sendiri.

Ada empat sisi reputasi dalam perspektif humas pemerintah, yaitu: Kredibilitas (Credibility) [6]. Mempunyai 3 karakteristik yaitu, memperlihatkan profitabilitas, dapat mempertahankan stabilitas dan adanya prospek pertumbuhan yang baik. Terpercaya (Trusworthiness). Karyawan percaya kepada organisasi sehngga karyawan dapat bekerja secara optimal dan rasa memiliki dan kebanggaan terhadap perusahaan. Keterandalan (Reliability). Selalu menjaga mutu produk atau jasa dan selalu melaksanakan pelayanan prima yang diterima di mata public. Tanggung Jawab (Responsibility). Membantu pengembangan dan peduli terhadap masyarakat sekitar Salah satu alasan masyarakat memilih suatu sekolah adalah reputasi sekolah tersebut.

[7] Dimensi yang digunakan dalam penelitian ini adalah cara mengukur reputasi menurut Charles, ada 5 (lima) dimensi yang digunakan, yang masing-masing mencakup beberapa indikator. Kelimanya adalah sebagai berikut: 
(1) Emotional Appeal (daya tarik emosional), meliputi: berperasaan baik, dan kekaguman,

(2) Lingkungan kerja pada institusi, meliputi: pengelolaan yang baik, kenyamanan lingkungan kerja bagi karyawan, karyawan terlihat senang melakukan pekerjaannya, memiliki karyawan dengan kinerja baik, dan karyawan terlihat disiplin kerja,

(3) Produk dan jasa institusi, meliputi: mendukung pelayanan yang diberikan, menawarkan kualitas pelayanan tertinggi, membuat inovasi dalam pelayanan, dan menawarkan pelayanan yang bernilai tinggi,

(4) Visi dan kepemimpinan institusi, meliputi: memiliki kepemimpinan yang baik, mempunyai visi yang jelas untuk masa yang akan datang dan visi dipahami karyawan,

(5) Tanggung Jawab Sosial, meliputi: mendukung majunya SDM Indonesia, kepedulian lingkungan dengan sekitar institusi, dan menjaga hubungan baik dengan orang-orang sekitar lembaga".

Dari kajian teori, dapat disusun Proposisi, sebagai berikut:

1. Jika manajemen pembelajaran seni budaya di implementasikan dengan baik, maka proses pembelajaran seni budaya akan berkualitas.

2. Jika proses pembelajaran seni budaya berkulitas, maka dapat meningkatkan reputasi sekolah.
Metode penelitian menggunakan penelitian pendekatan kualitatif, dengan tujuan untuk memperoleh gambaran mengenai : Manajemen Pembelajaran Seni Budaya Dalam Meningkatkan Reputasi Sekolah di SMP Negeri 4 Kalijati Subang. penelitian kualitatif adalah penelitian yang digunakan untuk mendeskripsikan dan menganalisis fenomena, peristiwa, aktivitas sosial, sikap, kepercayaan, presepsi, dan orang secara individual. Metode penelitian kualitatif sering disebut metode penelitian naturalistik karena penelitiannya dilakukan pada kondisi yang alamiah, disebut juga sebagai metode etnografi. Penelitian kualitatif dilakukan pada objek alamiah yang berkembang apa adanya, tidak dimanipulasi oleh peneliti dan kehadiran peneliti tidak begitu mempengaruhi dinamika pada objek tersebut. Penelitian kualitatif instrumennya adalah peneliti itu sendiri.

Parameter penelitian adalah suatu nilai atau kondisi yang dijadikan sebagai tolok ukur dalam menemukan segala sesuatu untuk mengisi kekosongan atau kekurangan yang ada, menggali lebih dalam apa yang telah ada, mengembangkan dan memperluas serta menguji kebenaran dari apa yang telah ada namun kebenarannya masih diragukan. Informan dalam penelitian ini adalah : Kepala Sekolah, Guru, Staff, Siswa, Orang Tua Siswa. Sedangkan pendapat para pakar, akan melibatkan Kepala Dinas Pendidikan dan Kebudayaan Kabupaten Subang, Pengawas Sekolah dan Sanggar Seni.

Operasionalisasi Parameter dalam penelitian ini adalah: 
Tabel 1: Operasionalisasi Parameter

\begin{tabular}{|c|c|c|c|c|c|}
\hline No & Rumusan Masalah & Dimensi & Indikator & Informan & $\begin{array}{c}\text { Teknik } \\
\text { Pengumpulan } \\
\text { data }\end{array}$ \\
\hline 1 & $\begin{array}{l}\text { Bagaimana } \\
\text { Manajemen } \\
\text { Pembelajaran Seni } \\
\text { Budaya }\end{array}$ & $\begin{array}{l}\text { 1.Perencanaan } \\
\text { 2.Organisasi } \\
\text { 3.Menggerakan } \\
\text { 4.Melakukan Evaluasi } \\
\text { 5.Melakukan perbaikan } \\
\text { 6.Hasil pembelajaran yang } \\
\text { terukur }\end{array}$ & $\begin{array}{l}\text { a.Intensitas, sistemik } \\
\text { dan sinergis antara guru } \\
\text { dan siswa } \\
\text { b.Iklim Pembelajaran } \\
\text { c.Media pembelajaran } \\
\text { d.Sarana dan Prasarana } \\
\text { Pembelajaran } \\
\text { e.Karakter : sikap } \\
\text { menghargai, kreatif, } \\
\text { kritis, tenang, } \\
\text { imajinatif, disiplin dan } \\
\text { produktif. }\end{array}$ & $\begin{array}{l}\text { 1). Guru } \\
\text { 2).Staff } \\
\text { 3).Siswa } \\
\text { 4).Orang } \\
\text { Tua } \\
\text { 5).Pengawas } \\
\text { Sekolah } \\
\text { 6).Dinas } \\
\text { Pendidik } \\
\text { An } \\
\text { 7.Pakar Seni } \\
\text { Budaya }\end{array}$ & $\begin{array}{l}\text { a. Wawancara } \\
\text { b. Observasi } \\
\text { c. Dokumentasi }\end{array}$ \\
\hline 2 & $\begin{array}{l}\text { Bagaimana } \\
\text { Meningkatkan } \\
\text { Reputasi Sekolah }\end{array}$ & $\begin{array}{l}\text { 1.Daya Tarik emosioal } \\
\text { 2.Lingkungan kerja pada } \\
\text { institusi } \\
\text { 3.Produk dan Jasa Institusi } \\
\text { 4.Visi dan Kepemimpinan } \\
\text { Institusi } \\
\text { 5.Tanggung Jawab Sosial }\end{array}$ & $\begin{array}{l}\text { 1.a.Berperasaab baik, } \\
\text { b.Kekaguman } \\
\text { 2.a.Pengelolaan yang } \\
\text { baik. } \\
\text { b.Kenyamanan } \\
\text { lingkungan. } \\
\text { c.Terlihat senang. } \\
\text { d.Disiplin } \\
\text { 3.a.Mendukung } \\
\text { pelayanan. } \\
\text { b.Kualitas pelayanan } \\
\text { tinggi. } \\
\text { c.Membuat inovasi } \\
\text { dalam pelayanan. } \\
\text { 4.a.Kepemimpinan } \\
\text { yang baik. } \\
\text { b.Visi yang jelas. } \\
\text { c.Visi dpahami. } \\
\text { 5. a.Mendukung SDM } \\
\text { Nasional } \\
\text { b.Kepedulian } \\
\text { lingkungan } \\
\text { c.Menjaga hubungan } \\
\text { baik }\end{array}$ & $\begin{array}{l}\text { 1).Guru } \\
\text { 2).Staff } \\
\text { 3).Siswa } \\
\text { 4).Orang } \\
\text { Tua } \\
\text { 5).Pengawas } \\
\text { Sekolah } \\
\text { 6).Dinas } \\
\text { Pendidik } \\
\text { An } \\
\text { 7.Pakar Seni } \\
\text { Budaya }\end{array}$ & $\begin{array}{l} \\
\\
\text { a. Wawancara } \\
\text { b. Observasi } \\
\text { c. Dokumentasi }\end{array}$ \\
\hline 3 & $\begin{array}{l}\text { Bagaimana } \\
\text { Manajemen } \\
\text { Pembelajaran Dapat } \\
\text { Meningkatk Reputasi } \\
\text { Sekolah }\end{array}$ & $\begin{array}{l}\text { 1.Prestasi di bidang Seni } \\
\text { dan Budaya } \\
\text { 2.Penerimaan Siswa Baru }\end{array}$ & $\begin{array}{l}\text { Kejuaran di Bidang } \\
\text { Seni Budaya } \\
\text { Jumlah siswa baru }\end{array}$ & $\begin{array}{l}\text { 1)Kepala } \\
\text { Sekolah } \\
\text { 2).Orang } \\
\text { Tua } \\
\text { 3)Pakar Seni } \\
\text { Budaya }\end{array}$ & $\begin{array}{l}\text { a. Wawancara } \\
\text { b. Observasi } \\
\text { c. Dokumentasi }\end{array}$ \\
\hline
\end{tabular}

Aktivitas dalam analisis data menurut Miles dan Huberman yaitu

1) Data reduction, yaitu merangkum, memilih hal-hal yang pokok, memfokuskan pada hal-hal yang penting, dicari tema dan polanya

2) Data display (penyajian data) dalam penelitian ini dilakukan dalam bentuk 
teks yang bersifat naratif, grafik, matriks dan bagan, chart, dsb

3) Conclusion drawing/Verification (Penarikan kesimpulan/ verifikasi) dapat berupa deskripsi atau gambaran suatu obyek secara jelas berupa hubungan interaktif atau kausal, hipotesis atau teori.

4) Dalam penelitian kualitatif kriteria utama terhadap data hasil penelitian ialah valid, realibel, dan obyektif.

[8] menyebutkan bahwa uji keabsahan data dalam penelitian kualitatif meliputi : uji credibility (validitas internal), transferability (validitas eksternal), depenability (reabilitas), dan confirmability (objektivitas). Untuk meganalisis data hasil wawancara dengan beberapa informan, peneliti menggunakan software NVIVO versi 12 pro. Tujuannya untuk lebih efektif dan efisien dalam pengolahan data, dengan menghasilkan beberapa gambar yang menjelaskan rumusan masalah dan proposisi penelitian. Melalui Word Similliarity (samaan Bahasan Dari Informan) dan Coding Similliarity (Kesamaan pengkodean yang dibuat berdasarkan persamaan maksud dari informan), juga Clustered by Word Similarity, yang akan menggambarkan keterkaitan antar variavel penelitian.

Sedangkan gambar hirarki chart, akan menggambarkan tumpukan kata-kata, dengan bentuk dan besar kecilnya kata yang beragam.

\section{HASIL PENELITIAN DAN PEMBAHASAN}

Hasil wawancara dengan Kepala Sekolah SMPN 4 Kalijati Subang, telah mengimplementasi dengan baik manajemen pembelajaran melalui pendekatan perencanaan, pengorganisasian, pengarahan, pengawasan dan evaluasi. Namun demikian masih ada kendala dalam penyediaan sarana prasarana untuk latihan seni, dalam hal ini seni tari. Sehingga masih diperlukan perhatian untuk memberikan fasilitas ruangan latihan.

Dari hasil wawancara dengan beberapa orang guru, dapat disimpulan bahwa dalam perencanaan pembelajaran seni budaya harus sesuai dengan kurikulum dan silabus KLKD. Pengorgnisasian, dengan memperhatikan minat bakat siswa dengan didukung sarana dan prasarana yang memadai. Pengarahan, memperkenalkan media pembelajaran seni budaya, sikap kooperatif guru dalam melaksanakan pembelajaran seni budaya, pembentukan karakter dan mengikuti kegiatan event-event seni budaya. Pengawasan, guru harus responsif terhadap peminatan siswa dan guru memberikan contoh yang baik. Sedangkan evaluasi, harus terukur melalui kualitas guru seni budaya, kebijakan, kepemimpinan, apreasiasi terhadap prestasi seni budaya, terukur reputasi sekolah.

Hasil wawancara dengan beberapa siswa SMPN 4 Kalijati Subang, secara umum siswa menilai manajemen sekolah dalam menyelenggarakan pembekajaran seni 
budaya dan menilai guru, siswa mendukung dan mengikuti proses pembelajaran dengan baik, serta merasa bangga dengan prestasi dari keikutsertaan pada berbagai kegiatan seni budaya. Pada umumnya siswa menyampaikan akan ikut berpartisipasi dalam, kegiatan proses pembelajaran seni budaya. Mengharapkan manajemen sekolah lebih memperhatikan dan mempertahankan prestasi di ajang seni budaya, agar reputasi sekolah dapat meningkat.

Hasil wawancara dengan beberapa orang tua siswa, sebagai perwakilan informan. Pada umumnya memberikan pendapat, bahwa orang tua sangat mendukung proses pembelajaran senin budaya, sepanjang sesuai dengan aturan dan tidak melanggaran kebijakan pemerintah. Orang tua sangat mendukung kegiatan proses pembelajaran senin budaya dan kegiatan esktrakurikuler / latihan seni. Orang tua sangat berharap dari kegiatan pembelajaran seni budaya dapat menghasilkan prestasi, yang dapat meningkatkan reputasi sekolah. Orang tua bangga.

Kepala Dinas Pendidikan Kabupaten Subang mengatakan bahwa penting nya manajemen proses pembelajaran seni budaya, dimana (a) perencanaan merupakan proses rangkaan urutan rasional dalam menyusun rencana (manajemen pembelajaran seni budaya dalam meningkatkan reputasi sekolah di SMPN 4
Kalijati Subang); (b) pengorganisasian, yaitu proses mengatur orang dan sumber daya lainnya, untuk bekerja kea rah tujuan Bersama, yaitu meningkatkan reputasi sekolah di SMPN 4 Kalijati Subang; (c) pengarahan, sesuai dengan penelitian tesis, diharapkan banyak manfaatnya untuk kepentingan jangka Panjang dan (d) pengawasan, semua aktivitas yang dilaksanakan, upaya memastikan bahwa hasil akhir sesuai dengan hasil yang direncakan.

Dengan demikian Kepala Dinas Pendidikan Kota Subang, mendukung terhadap hasil penelitian Tesis. Jika prestasi bidang senin budaya ditingkatkan, akan memberikan kontribusi terhadap reputasi sekolah.

Proses pembelajaran seni budaya yang dikembangka di sekolah SMPN 4 Kalijati Subang, sangat setuju, dengan memadukan antara teori dengan praktek. Melalui pembelajaran seni budaya di sekolah, secara tidak langsung telah memperkenalkan budaya setempat. Melalui pembelajaran seni budaya , siswa SMPN 4 Kalijati Subang dapat mencintai budaya sendiri, tanpa menolak seni budaya modern, yang masuk ke lingkungan sekolah.

Semoga anak-anak- siswa SMPN 4 Jalijati Subang, memilik karakter ketimuran, sehingga bisa dihormati oleh negara lain manca negara. 

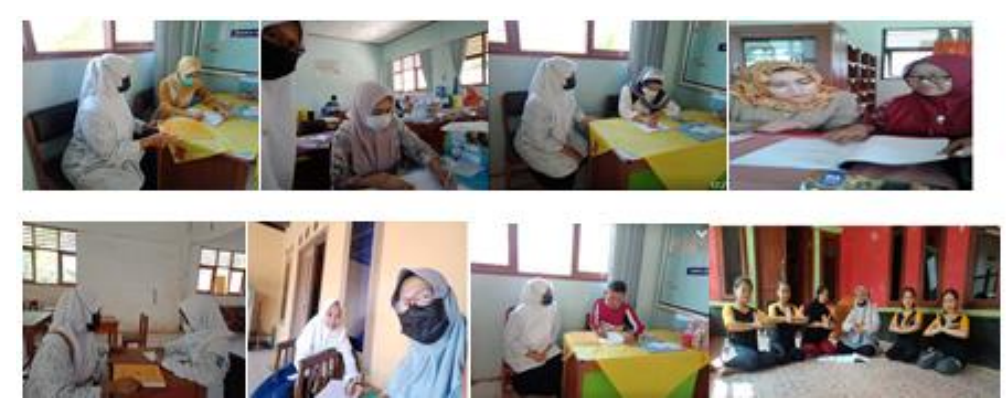

Gambar 3: Hasil wawancara

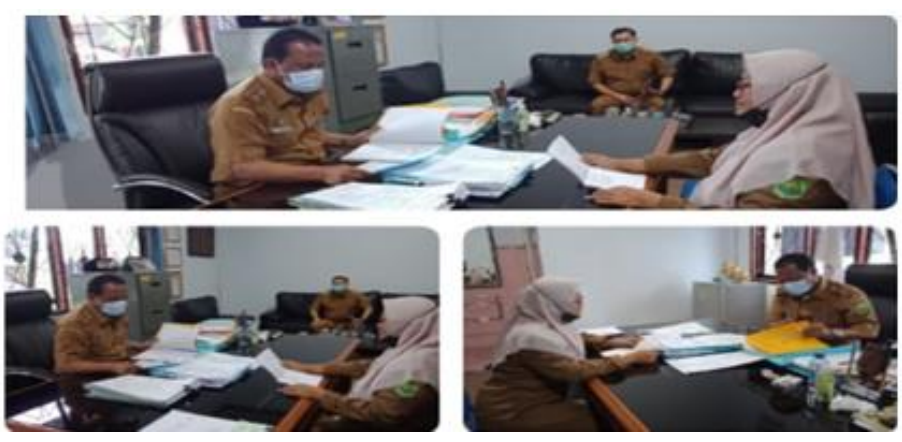

Gambar 4: Hasil wawancara

Hasil analisis dengan menggunakan software NVivo pro12, diperoleh beberapa gambar yang menjelaskan rumusan masalah dan proposisi penelitian. Melalui Word Similliarity (samaan Bahasan Dari Informan) dan Coding Similliarity (Kesamaan pengkodean yang dibuat berdasarkan persamaan maksud dari informan).

Pada gambar hirarki chart, dapat terlihat tumpukan kata-kata, dengan betuk dan besar huruf yang tidak sama. Semakin besar bentuk/ kata huruf, menunjukan dominasi dari variabel yang digunakan dalam penelitian. Kata budaya dan seni serta pembelajaran merupakan kata yang paling menonjol. Hal ini menunjukkan bahwa Pembelajaran Seni Budaya merupakan kegiatan yang penting dan memberikan pengaruh yang besar dalam membangun reputasi sekolah.

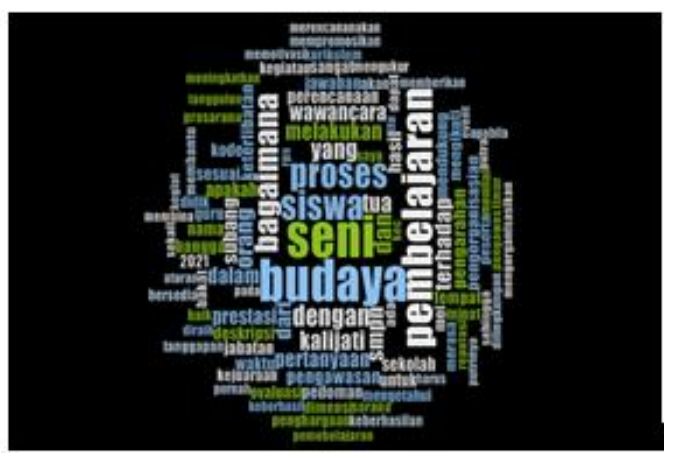

Gambar 5: Hierarki Chart

Berdasarkan analisis melalui Nvivo12 adalah

Hierarki Chart. Hierarki chart ialah diagram yang dapat menunjukkan data hirarki berbentuk persegi panjang dengan berbagai ukuran dan juga dapat melihat hierarki chart dalam bentuk bulat, Dari berbagai ukuran tersebut ditentukan dengan menunjukkan jumlah contohnya jumlah coding pada nodes 
atau jumlah referensi dari koding yang dimasukkan sesuai dengan isi artikel yang ditemukan oleh peneliti. Hierarki chart skala terbaik sesuai dengan ruang yang tersedia sehingga ukuran - ukuran persegi panjang harus dipertimbangan dengan hubungan satu dengan yang lainnya, bukan dalam bentuk angka absolut. Daerah terluas ditampilkan pada bagian kiri atas grafik, sedangkan daerah terkecil ditampilkan pada bagian bawah kanan grafik. Penelitian ini,menggunakan hierarki chart dikarenakan peneliti ingin melihat dominasi tentang seni budaya.
Berdasarkan hasil analisis NVIVO 12 Pro berdasarkan clustered by Word Similarity dan Clustered by Word Similarity, dapat dilihat bahwa variabel evaluasi pembelajaran, mendukung minat, pengawasan, perorganisasian, pengarahan dan perencanaan pembelajaran dan mendukung budaya berda pada titik yang saling berdekatan. Hal ini menunjukkan adanya keterikatan antar variabel satu sama lainnya. Keterkaitan antar variabel didasarkan pada kesamaan kata yang diberikan oleh informan kepada peneliti.

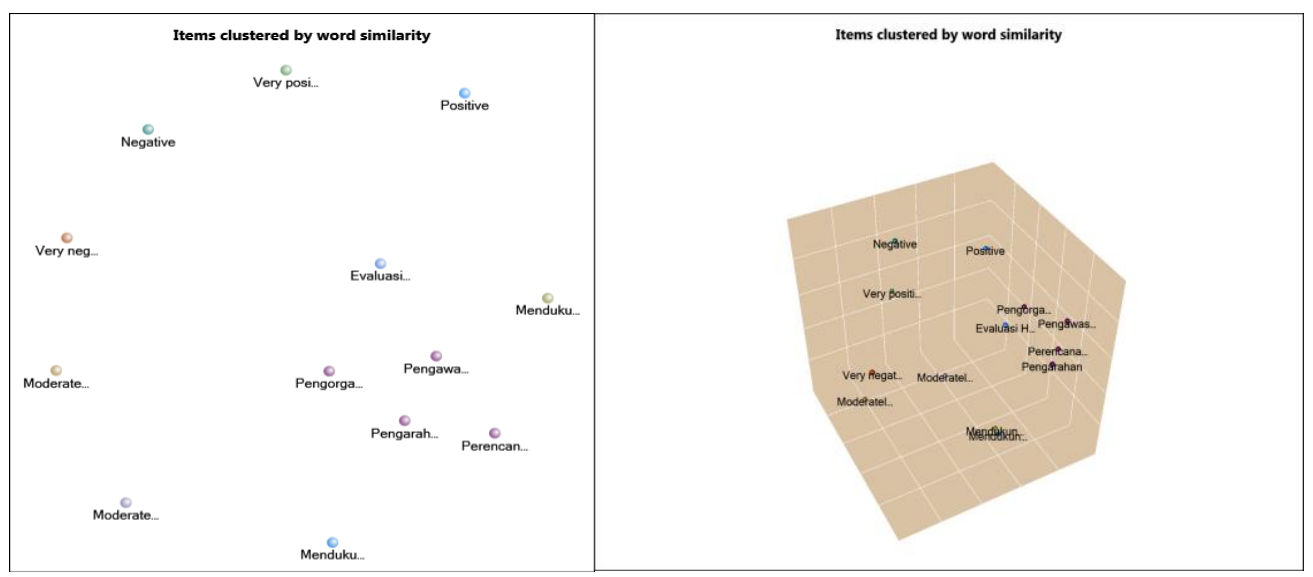

Gambar 6:Clustered by Word Similarity \& Clustered by Word Similarity

Penelitian sebelumnya menunjukkan pembelajaran seni budaya yang telah dilaksanakan dengan menggunakan metode penguatan dengan tahapan di atas dapat meningkatkan prestasi belajar siswa [8]. Namun, Pemberian penguatan tidak secara langsung meningkatkan prestasi belajar, melainkan harus melalui tahapan motivasi belajar, dan setelah hal itu tercapai maka prestasi belajar juga akan meningkat. Sedangkan dari hasil penelitian lain menyatakan bahwa kontribusi pendidikan seni budaya sangat signifikan untuk pembinaan karakter anak didik dan karakter bangsa [9].

\section{KESIMPULAN}

1. Manajemen pembelajaran seni budaya di SMPN 4 Kalijati Subang, sudah dilakukan sesuai dengan aspek fungsifungsi manajemen, Planning, Organizing, Actuating dan Controlling. Namun demikian masih ada keterbatasan, sehingga implementasi manajemen pembelajaran seni budaya 
belum optimal. Secara teknis kegiatan pembelajaran seni budaya dilakukan sesuai Kurikulum dan Silabus. Namun demikian implementasi kegiatan latihan seni tari, masih harus diperhatikan kualitas dan kuantitas Guru pengajar, juga sarana prasarana yang dapat menunjang kreativitas siswa di bidang seni budaya. Melalui pembelajaran seni budaya, diharapkan siswa dapat lebih mengenal budaya lokal, dan merasa bangga dengan kekayaan budaya lokal. Disampaing harus mengenal keragaman seni budaya nasional dan asing;

2. Untuk meningkatkatkan reputasi sekolah di SMPN 4 Kalijati Subang, tentunya banyak sekali faktor yang akan menertukan reputasi sekolah. Salah satunya melalui kegiatan lomba seni budaya. Sudah cukup banyak prestasi yang di raih siswa dan guru dalam kegiatan seni budaya, walaupun masih dalam skala local. Tentunya diharapkan;

3. Manajemen pembelajaran seni budaya yang telah dilakukan oleh Kepala Sekolah sebagai di SMPN 4 Kalijati Subang, diharapkan dapat meningkatkan reputasi sekolah. Beberapa kegiatan lomba yang di ikuti siswa, telah menunjukan prestasi. Tentunya menjadi kebanggaaan bagi sekolah, guru, siswa dan orang tua siswa. Walaupun kejuaraan yang diperoleh masih pada skala lokal. Hasil wawancara dengan Guru, siswa dan orang tua siswa, menunjukkan kebanggaan atas prestasi seni budaya yang telah di raih selama ini. Diharapkan dapat meningkatkan kepercayaan masyarakat terhadap SMPN 4 Kalijati Subang.

\section{DAFTAR PUSTAKA}

[1] Eko Purnomo. 2014., Seni Budaya., Pnerbit Kementrian Pendidikan dan Kebudayaan

[2] Sri Nurabdiah Pratiwi . 2016

[3] Eko Purnomo. 2014., Seni Budaya., Pnerbit Kementrian Pendidikan dan Kebudayaan

[4] Hetty Tumurang. 2006., Pembelajaran Kreatif Seni. Anak Sekolah Dasar. menanamkan kreativitas dan sensibilitas peserta didik .

[5] Dewey, Read dan Ross

[6] Charles Fombrun dalam MS. Eric Santosa. 2018., Jurnal Ketersediaan Informasi dan Reputasi Institusi terhadap Kepercayaan Mahasiswa dan Dampaknya pada Niat Registrasi Ulang (Studi pada Sekolah Tinggi Ilmu Farmasi "Yayasan Pharmasi" Semarang), Equilibrium Jurnal Bisnis \& Akuntansi Volume XII, No. 1 (April 2018): $1-16$

[7] Fombrun dalam MS. Eric Santosa $(2018: 5)$

[8] Sugiyono. 2007., Metode penelitian kuantitatif, kualitatif dan kombinasi (mixed methods), Penerbit: Penerbit Alfabeta

[9] Sutarto. 2015. Dasar-dasar Organisasi Penulis Sutarto - UGM Press, 